\title{
Implementasi Pembayaran SPP Berbasis WEB Pada Sekolah Menengah Pertama (SMP) Muhammadiyah Kota Medan
}

\author{
Indah Purnama Sari ${ }^{1}$, Fatma Sari Hutagalung ${ }^{2}$, Budi Kurniawan Hutasuhut ${ }^{3}$ \\ Program Studi Sistem Informasi, Fakultas Ilmu Komputer dan Teknologi Informasi \\ Universitas Muhammadiyah Sumatera Utara, Jl. Kapten Muchtar Basri No. 3 Medan \\ 20221 \\ e-mail : indahpurnama@umsu.ac.id
}

\begin{abstract}
Informasi Artikel
Diterima Redaksi : 10 Juli 2020

Revisi Akhir : 07 September 2020

Kata Kunci:

Pembayaran, SPP, Teknologi.
\end{abstract}

Diterbitkan Online : 26 Oktober 2020

\begin{abstract}
Abstrak
Perkembangan teknologi di era saat ini berkembang sangat pesat, hal ini terbukti dengan banyaknya penggunaan jaringan internet di berbagai kalangan masyarakat saat ini. Seperti halnya pendidikan untuk mengetahui layanan informasi pembayaran SPP. Pada tingkat pendidikan Sekolah Menengah Pertama (SMP), belum banyak sekolah yang mengenal dan memanfaatkannya dengan baik teknologi ini. Salah satunya yaitu sekolah SMP Muhammadiyah dalam kegiatan pelayanan administrasi pembayaran SPP, masih dilakukan secara manual dengan melakukan pencatatan manual kedalam sebuah buku besar, lamanya dalam proses antrian pembayaran SPP, dan sering melakukan kesalahan dalam hasil pembuatan laporan, sehingga sistem yang berjalan saat ini belum optimal, karena itu perlu adanya peningkatan sistem secara terkomputerisasi pada laporan pembayaran SPP. Sebagai media penghubung antara wali murid dan pihak sekolah, agar wali murid dapat mengecek pembayaran putra putrinya setiap bulannya. Oleh karena itu perlu diadakan penelitian dan membuatkan sebuah sistem baru yang dapat dimanfaatkan untuk pembayaran SPP yang bertujuan untuk meningkatkan keakuratan, kecepatan, serta ketetapan dalam pembuatan laporan sehingga mengurangi kesalahan dalam laporan pembayaran. Sistem yang baru dapat memaksimalkan pekerjaan bendahara dalam penyampaian informasi pembayaran, ketelitian maupun pelayanan administrasi pembayaran SPP dapat dilakukan secara efektif dan efisien.
\end{abstract}

SMP Muhammadiyah merupakan institusi yang bergerak dalam bidang pendidikan. Sekolah membutuhkan suatu pengelolahan administrasi dengan menyediakan data - data guna untuk melakukan proses pencatatan pembayaran SPP sekolah. Pencatatan pembayaran memiliki peran penting dalam menunjang kegiatan pembelajaran dan operasional sekolah, sehingga tertatanya pencatatan menjadi poin kunci untuk keberlangsungan pembayaran.

Proses pengelolahan pencatatan pembayaran SPP membutuhkan tingkat ketelitian dalam prosesnya, hal ini berkaitan mengenai pelaporan keuangan perbulan, pelaporan lunas iuran dan pelaporan 
tunggakan perbulan yang dilaporkan ke kepala sekolah dan komite sekolah. Proses pencatatan pembayaran SPP dilakukan secara mandiri oleh siswa yang dimulai dari siswa mendatangi loket pembayaran, selanjutnya memberikan kartu pembayaran SPP beserta uang pembayaran yang kemudian akan dicatat oleh pihak bendahara sekolah di dalam buku pembayaran SPP dan kartu pembayaran.

Permasalahan muncul ketika bendahara melakukan rekapan data siswa yang sudah membayar dan yang belum membayar SPP, hal ini menyebabkan banyaknya waktu yang terbuang. Selain itu, buku catatan pembayaran akan menjadi rusak sehingga pelaporan pembayaran perbulan menjadi terlambat. Berdasarkan permasalahan diatas, maka dibuat aplikasi pengelolahan pencatatan pembayaran SPP berbasis WEB sebagai salah satu segi layanan yang digunakan untuk menunjang kegiatan kebendaharaan dengan adanya pengelolahan pencatatan pembayaran SPP, pencatatan dan pelaporan dapat diproses dengan cepat dan tepat.

\section{METODE}

\subsection{Tahapan - Tahapan Penelitian}

Tahapan - tahapan dari metode pelaksanaan : Dimulai dari peninjauan mitra yang bertujuan untuk mengetahui permasalahan yang ada pada mitra, dari tinjauan yang kami lakukan menyusun proposal yang bertujuan untuk mempermudah pembuatan aplikasi dan modul, persiapan komponen untuk pelatihan sangat penting pada saat pelaksanaan pelatihan di tempat mitra, kemudian evaluasi sangat diperlukan setelah melakukan pengabdian sehingga tim mengetahui sejauh mana progress yang kami jalankan sebelum dibuatkan laporan pengabdian.

\subsection{Teknik Pengumpulan Data}

Adapun teknik pengumpulann data penulis dalam menyelesaikan penelitian ini dengan cara sebagai berikut :

\section{Studi Kepustakaan}

Studi kepustakaan merupakan salah satu teknik pengumpulan data dengan mencari teori-teori yang telah dikembangkan dalam bidang ilmu yang berhubungan dengan pembuatan aplikasi serta melakukan referensi dengan buku-buku yang berkaitan dengan masalah yang penulis angkat.

\section{StudiWawancara}

Studi wawancara adalah salah satu teknik pengumpulan data dengan cara wawancara (interview) guna mengumpulkan data-data yang diperlukan.

\section{Eksplorasi Internet}

Yaitu dengan cara membuka situs-situs yang berhubungan dengan tema yang diangkat dalam penyusunan penelitian ini.

\section{HASIL DAN PEMBAHASAN}

\subsection{Analisa Sistem Yang Sedang Berjalan}

Berdasarkan wawancara dan observasi yang dilakukan, diketahui bahwa sistem pembayaran spp di SMP Muhammadiyah yang sedang berjalan belum memanfaatkan teknologi sepenuhnya. Berikut adalah gambaran dari sistem yang sedang berjalan di SMP Muhammadiyah :

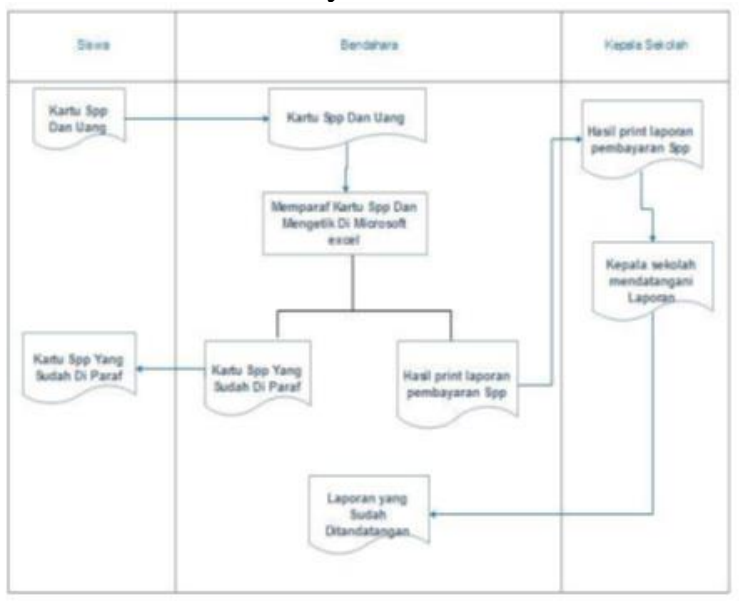

Gambar 1. Sistem Yang Sedang Berjalan

\subsection{Analisa Sistem Yang Diusulkan}

Setelah menganalisa hasil wawancara dan observasi yang dilakukan penulis, maka diperlukan suatu sistem yang dapat memudahkan admin (tata usaha bagian keuangan) dalam pembuatan laporan dengan memanfaatkan sistem informasi pembayaran spp. 


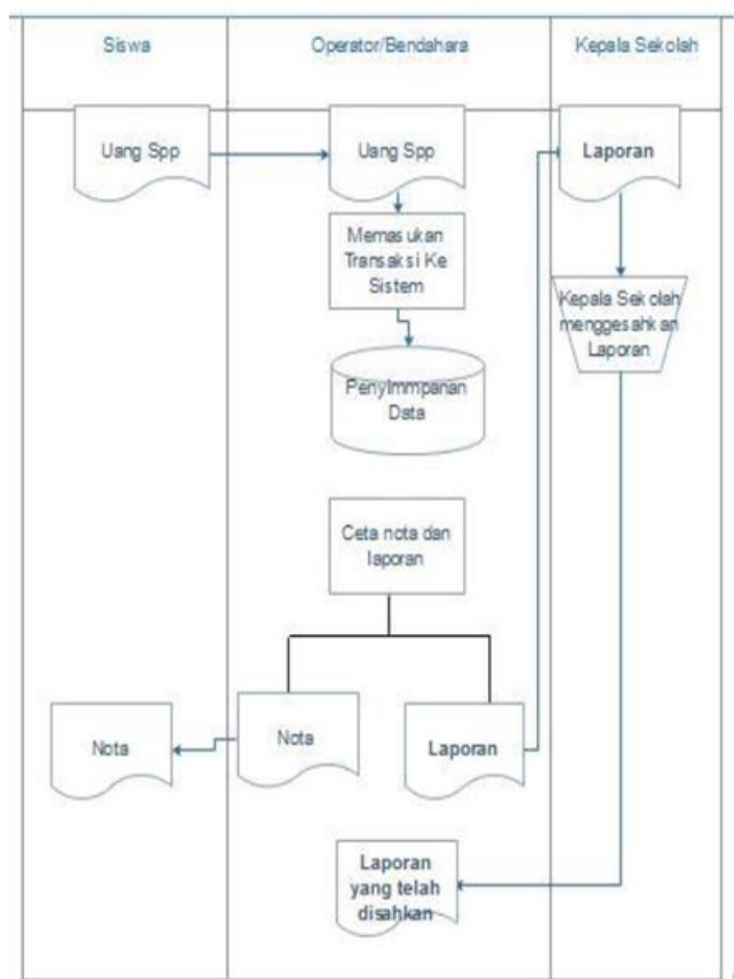

Gambar 2. Sistem Yang Diusulkan

\subsection{Rancangan Use Case Diagram}

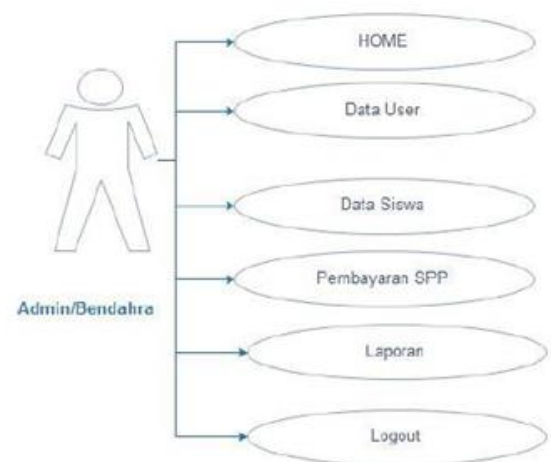

Gambar 3. Use Case Diagram

\subsection{Implementasi Sistem}

3.4.1 Tampilan Output Pembayaran SPP

Tampilan ini akan menampilkan data pembayaran spp, yang dikelola oleh admin untuk dibuatkan laporan kepada kepala sekolah.

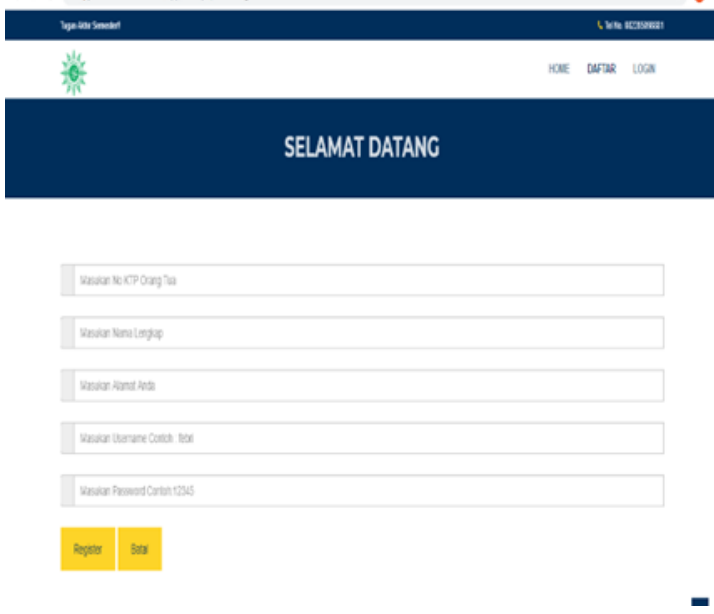

Gambar 4. Tampilan Output Pembayaran SPP

\subsubsection{Tampilan Form Input Data Siswa}

Pada tampilan ini, akan menampilkan mengenai form input siswa.

\section{SELAMAT DATANC}

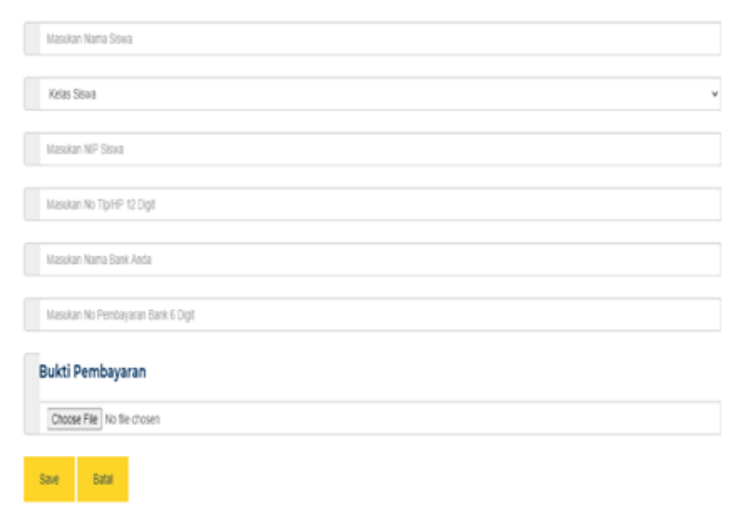

Gambar 5. Tampilan Form Input Data Siswa

\section{KESIMPULAN}

Berdasarkan uraian yang dikemukakan sebelumnya, maka dapat disimpulkan sebagai berikut :

1. Sistem informasi pembayaran spp berbasis web di SMP Muhammadiyah, dapat memudahkan admin atau staff dalam mengolah data pembayaran spp.

2. Mempermudah staff memberikan laporan pembayaran spp kepada atasan.

3. Penyimpanan data dalam database memudahkan dalam penyimpanan dan pemeliharaan data, sehingga kita bisa mengetahui data-data yang 
dibutuhkan dengan cepat dan akurat. Dan dapat dilakukan setiap saat bila dibutuhkan.

\section{SARAN}

Agar tujuan efektifitas dan efisiensi kerja dapat tercapai, maka penulis mengajukan beberapa saran sebagai berikut

1. Tersedianya sumber daya manusia yang dapat mengoperasikan sistem ini, agar dapat berjalan sesuai dengan yag diharapkan.

2. Sistem pembayaran spp yang telah ada sebainya perlu ditata, di update sesuai dengan perkembangan teknologi, karena teknologi bisa dikatakan perkembangannya perdetik sehingga dapat meningkatkan sistem kerja pada SMP Muhammadiyah.

\section{UCAPAN TERIMA KASIH}

Ucapan terimakasih penulis sampaikan kepada :

1. Bapak Dr Agussani, M.AP, selaku Rektor Universitas Muhammadiyah Sumatera Utara.

2. Lembaga Penelitian dan Pengabdian Masyarakat (LP2M) Universitas Muhammadiyah Sumatera Utara.

3. Bapak Dr. Akrim, S.Pd.I, M.Pd, selaku Dekan FIK-TI Universitas Muhammadiyah Sumatera Utara.

4. Bapak Lutfi Basit, S.Sos, M.I.Kom, selaku Ketua Jurusan FIK-TI

Universitas Muhammadiyah Sumatera Utara.

5. Bapak Al-Khowarizmi, S.Kom, M.Kom, selaku Sekretaris Prodi Sistem Informasi Universitas Muhammadiyah Sumatera Utara.

6. Ibu Fatma Sari Hutagalung, S.Kom, M.Kom, selaku rekan dalam pelaksanaan pengabdian ini dan selaku Dosen FIKT-TI Universitas Muhammadiyah Sumatera Utara.

7. Bapak Budi Kurniawan, S.Kom, M.Kom, selaku rekan dalam pelaksanaan pengabdian ini dan selaku Dosen FIK-TI Universitas Muhammadiyah Sumatera Utara.

\section{REFERENSI}

[1] Abdul Kadir. 2014. Pengenalan Sistem Informasi Edisi Revisi.Andi.Yogyakarta.

[2] Bramanto Aji Maulana Fakultas Ilmu Komputer, Universitas DianNuswantoro Semarang.

[3] Hendrik Ika Dita Widia: Sistem Informasi Pembayaran SPP pada SMK Pawyatan Daha 3 Kediri, Skripsi, SI, FT UN PGRI Kediri, 2017.

[4] Pembangunan Sistem Informasi Administrasi Pembayaran SiswaMadrasah Aliyah Ma'arif Pacitan Ali Syahbanaasyahbana12@yahoo.co.id.

[5] Sistem Informasi Pembayaran Biaya Operasional Sekolah SiswaPada "Bank Mini Arta Prima" Sekolah Menengah Kejuruan Negeri 2 PacitanNovitasari 1) Indah Uly Wardati 2)eyascout@yahoo.com. 